\title{
PANORAMA DA EDUCAÇÃO NA REGIÃO DO CONTESTADO APÓS CEM ANOS DA GUERRA DO CONTESTADO
}

\author{
Geraldo Antônio da Rosa ${ }^{1}$ \\ Nilson Thomé ${ }^{2}$
}

\section{RESUMO}

O presente artigo pretende fazer reflexões a partir de pesquisas realizadas pelos autores sobre um panorama da educação na Região do Contestado após cem anos da Guerra do Contestado, um dos grandes conflitos rurais do Brasil acontecido entre os anos de 1912 a 1916. Num primeiro momento busca-se fazer uma análise dos aspectos geopolíticos da região procurando salientar o processo de povoamento. Para entender o momento atual o trabalho tenta caracterizar o homem do Contestado, os aspectos econômicos da região, bem como a estruturação social responsável pelos mecanismos de poder altamente centralizados. Torna-se importante ressaltar a evidente falta de instrução, de escolas, de meios de comunicação, assim como a presença de um homem revoltado por falta de justiça. A educação, nesse momento, acompanhou as mudanças da época, servindo de sustentáculo à estrutura social dominante. $\mathrm{O}$ que se observou foram ações centralizadoras, marcos do processo de educação opressora que se reproduz na sociedade até os dias atuais. Nesse ambiente, os homens foram alienados, marcados pelo terror branco que gerou a cultura do medo e do silêncio. Para não despertá-los para a busca de seus direitos, foi necessário educá-los para que se tornarem passivos e domesticados. Essa lógica instituída na educação formal e informal da região fez parte do passado e da realidade presente. A história da região transmitida através dos tempos foi a história oficial, ou seja, a história do Estado trabalhada numa perspectiva positivista, enaltecendo heróis, fatos, famílias tradicionais, coronéis e, relegando a maioria da população a meros coadjuvantes da "verdadeira história".

Palavras-chave: Educação; Região do Contestado; Guerra do Contestado

\section{PANORAMA OF EDUCATION IN THE CONTESTADO REGIOM BEFORE THE HUNDRED YAEARS SINCE THE CONTESTADO WAR}

\begin{abstract}
This article aims to make reflections through the researches performed by the author about a panorama of the education in the Contestado Region before the hundred years since the Contestado War, one of the biggest rural conflicts in Brazil. Firstly, it searches for doing an analysis about the geopolitical aspects of the region, looking for emphasizing the populating process. For understanding the actual moment this work tries to charactering the Contestado man, political aspects of the region, as well the social structuring which is responsible to the highly centralized mechanisms of power. It's important to just out that, inside of that structure, the miss of instruction is evident, of schools, of ways of communication, as well the presence of a rebel people against the absence of justice. The education, in that moment, followed the changes of that epoch serving like a supporter to the dominant social structure. Inside this reality structures the process of education of the Contestado peasants. This domination has passed by generations being the formal and informal educational process back to the passivity, that is, to the adaptation to the world, instead of becoming people historic subjects, architect, and designers of projects backed to the social changes. What it can be observed in that society are centralizer actions, boundary
\end{abstract}


of the process of oppressor education which reproduces in this society in the current days. In that environment, the people are guided, being marked by the white terror that creates the fear and silent culture. The marginalized are victims and consequences of that oppresive society. That logic established in the formal and informal education of the region is a part of the past and the present reality. The history of the region transmitted through the time was an official history, that is, the history of the state worked in a positivist perspective, extolling heroes, facts, traditional families, colonels and, banishing the bigger part of ht epopulation to simple co-operators of the "true history".

Keywords: Education; Contestado Region; Contestado War

\section{Aspectos históricos e geopolíticos da região}

Para se traçar um panorama concernente à História da Educação na atualidade dessa região, relegada pela historiografia oficial, buscando transcender uma visão marcada pelo determinismo geográfico, necessário se faz analisar os aspectos socais, políticos e econômicos estruturantes e suas marcas após cem anos de um dos maiores conflitos rurais do Brasil.

Antes de qualquer análise buscou-se identificar aspectos que aproximam a caracterização da região. A denominação de Região do Contestado prende-se ao fato de ter sido alvo de disputa internacional entre o Brasil e a Argentina, conhecida historicamente como Questão de Palmas. Essa disputa foi resolvida de forma pacífica através do arbitramento do presidente Cleveland dos Estados Unidos da América, que deu ganho de causa ao Brasil. Também foi esse espaço o motivo para uma disputa interestadual, a partir de 1853, entre os estados de Santa Catarina e do Paraná, tendo vários desfechos em diferentes momentos. O litígio teve seu desfecho final de forma pacífica em 1916; após várias contendas judiciais, ele foi resolvido na justiça entre os estados de Santa Catarina e do Paraná.

Para um maior entendimento da região na atualidade, torna-se imprescindível analisar a ocupação territorial, a partir da lógica ocupacional de Santa Catarina. O povoamento do Estado de Santa Catarina seguiu a lógica do povoamento brasileiro, ou seja, o litoral tinha aberto suas portas para o contato dos mais diferentes povos, enquanto que o planalto sofreu o isolamento da Serra Geral. Na segunda metade do século XVII, surgiram três povoações, no litoral, que marcaram as primeiras cidades: Nossa Senhora da Graça do Rio São Francisco, Nossa Senhora do Desterro e a de Santo Antônio dos Anjos da Laguna.

Em 1765, Morgado Mateus, Presidente da Capitania de São Paulo, ordenou a Correia Pinto o povoamento do planalto catarinense. De acordo com Cabral

Correia Pinto chegou ao local da nova povoação, nas Taipas, em novembro de 1766 e logo iniciou o levantamento de uma capela de madeira, onde já existia uma ermida de tropeiros, colocando-a sob a invocação de Nossa Senhora dos Prazeres, da especial devoção de Morgado. (CABRAL, 1979, p. 39).

A fundação da Vila Serrana, hoje Lages, foi de fundamental importância para o povoamento do Planalto Catarinense e de suas adjacências. Santa Catarina foi elevada à categoria de Província em meados do século XVIII, criando celeuma na questão de limites com a Província de São Paulo. A Província do Paraná, criada na metade do século XIX, começou a litigar com a Província de Santa Catarina. Segundo Cabral, em 1846 a Comissão de Estatística da Câmara dos Deputados reconhecia os limites entre Santa 
Catarina e o Rio Grande do Sul, pelo Projeto Livramento. Cabral evidencia:

Neste mesmo ano, o Paraná reivindicava uma linha divisória com Santa Catarina que lhe arrebataria não só os Campos de Palmas mas a maior parte da Comarca de Lajes, os Campos Novos e Curitibanos, propondo as lindes pelo Rio Canoas, da sua confluência no Pelotas até à do Marombas, por este até a sua nascente principal e daí em linha reta na direção leste até a serra do Mar e por esta até o paralelo da nascente do Rio Saí. (CABRAL, 1979, p.59).

Com a Proclamação da República, a região era alvo de disputa entre o Brasil e a Argentina, conhecida historicamente como a Questão de Palmas. A partir de 1896, de acordo com Cabral, Santa Catarina e o estado do Paraná começam a disputa por territórios. O governador da época, Hercílio Luz, segundo Cabral entregou a defesa dos direitos catarinenses a "Manoel da Silva Mafra, político e Magistrado Catarinense [...] Mafra, em 1899, publicou a sua Exposição Histórico-Jurídica por parte de Santa Catarina sobre a questão de limites com o Estado do Paraná [...]”. (CABRAL, 1979, p.56).

Por parte do estado do Paraná houve várias tentativas de embargo às decisões do Supremo Tribunal Federal de 1904, que deu ganho de causa ao estado de Santa Catarina. Em 1909, ocorreu um novo pronunciamento favorável a Santa Catarina, e, em 1910, o Supremo Tribunal Federal confirmou as decisões anteriores suspendendo os embargos solicitados pelo estado do Paraná.

Cabral assim descreve o final da disputa:

Finalmente, removidos os últimos obstáculos, a 20 de outubro de 1916, assinaram os Governadores de Santa Catarina e do Paraná, drs. Filipe Schmidt e Afonso Camargo, juntamente com o Presidente da República, o ato do Acordo que iria colocar um ponto final ao secular pleito que os anseios expansionistas do Morgado Mateus haviam provocado. (CABRAL, 1979, p. 64).

\section{O homem do contestado - os primeiros habitantes da região}

Um dos questionamentos de fundamental importância e de caráter idiossincrático encontra-se intimamente relacionado às raízes de um povo. Sua origem encontra-se ligada a elementos sócio-históricos que cristalizam sua identidade. No período que antecedeu a chegada dos dominadores europeus, já se faziam presentes na região, dedicando-se à coleta e à caça, os índios Kaigang e os Xocrén. É importante destacar que grande parte do contingente indígena foi dizimada pela ação dos bugreiros que eram sertanistas contratados para defender os interesses do capital. Pouco se tem produzidos em termos de pesquisa a respeito da nefasta ação desses sertanistas, entretanto tem-se em plena evidência seus efeitos.

No século XVI, começaram a transitar pela região os europeus no litoral de Santa Catarina e no interior do Paraguai. As três povoações litorâneas, que serviram de base para a fixação e a expansão do Estado de Santa Catarina e que acolheram os açorianos foram: São Francisco, Desterro e Laguna.

Durante o ciclo do ouro, começou o povoamento do planalto catarinense em virtude de ser o caminho das tropas que ligavam Viamão, no Rio Grande do Sul, às feiras de Sorocaba. A região passou a ser conhecida pelos tropeiros que conduziam tropas de gado até a região de Sorocaba, no Estado de São Paulo, servindo posteriormente para abastecer a região mineradora das Minas Gerais. Nesse trajeto, desenvolveram-se pontos 
de paradas, ou pousadas, que mais tarde iriam proporcionar o surgimento de cidades que hoje se constituem em pólos regionais.

A respeito do caminho das tropas, Valentini faz o seguinte destaque:

O caminho das tropas ou Rota dos sertões para Viamão, depois de vários esboços, ganha forma em 1728, tornando-se conhecido. O primeiro a fazer a travessia dos sertões foi Cristóvão Pereira de Abreu, logo após, em 1831, Francisco de Souza e Faria atravessou a serra acima. O trajeto foi encurtado e as passagens foram melhoradas, abrindo-se enfim, o caminho que desempenharia importante papel econômico, social e político. Vinha direto do sul, cruzando o Pelotas. Era o caminho por onde transitavam todos os anos milhares de mulas, cavalos e gado vacum, que iriam fazer de Sorocaba o centro da maior feira do país. (VALENTINI, 1998, p. 29).

Deve-se destacar como fator de desenvolvimento a Estrada das Tropas, que serviu como caminho de ligação do Sul do Brasil ao Centro. Principalmente essa estrada foi utilizada no transporte de gado de Viamão, no Rio Grande do Sul, até Sorocaba, em São Paulo. De acordo com Vinhas de Queiroz: "Cortava de sul para o norte [...]. Após percorrer os campos de Lages, ganhava Curitibanos, rompia uma extensa faixa de floresta virgem as matas do Rio Negro -, até que ia sair nos Campos Gerais do Paraná, no rumo de Itararé”. (QUEIROZ, 1977, p.24).

Vinhas de Queiroz (1977), salienta ainda que, na região de cima da serra, as posses precárias das terras aos poucos foram se transformando em propriedades definitivas. Correia Pinto, fundador de Lages, ao chegar à região destacou a existência de estancieiros empobrecidos, ancestrais dos futuros caboclos, servos foragidos e antigos camaradas das tropas de burro que ficavam pelos caminhos. Nesse contexto, ficou uma população excluída do processo e, ao mesmo tempo, sujeito à lógica do capital. A partir de 1820, Lages passou a fazer parte da Província de Santa Catarina. No que se refere à estrutura fundiária, Queiroz destaca: "Entre outras razões, consagrou-se em todo país, inclusive aqui, o costume através do qual o simples apossamento da terra garantia a propriedade. Até a lei Agrária de 1850, este ato se tornou o único processo lícito de adquirir propriedade nova". (QUEIROZ, 1977, p.26).

Por outro lado, Cabral (1979), enfatiza a existência de uma barreira natural, entre o litoral e o interior, destacando a diferença existente entre os homens que habitavam além dessa barreira, em termos de costumes, cultura e história. Os primeiros homens que cortaram o litoral norte foram os tropeiros. Subiram o Morro dos conventos, vencendo a íngreme Serra do Mar, e rumando com suas tropas a Sorocaba. Os tropeiros tinham locais que eram as marcas de pouso, porém de início não serviram como pontos de fixação.

\section{A estruturação social como base de um poder centralizado}

Tendo a região a pecuária como principal atividade econômica, a sociedade foi estruturada, como podemos classificar, de pastoril marcada pela centralidade das decisões pelos senhores proprietários das terras e dos gados. As tarefas da lida do campo e as mais pesadas eram repartidas entre escravos agregados, peões e capangas, esses estavam ligados aos proprietários da terra por um vínculo de lealdade absoluta, subserviência e dependência econômica.

Cabral (1979), faz uma análise destacando que os agregados tinham uma afeição quase que familiar por seus patrões, participavam das agruras da vida, porém não compartilhavam da prosperidade. As benesses que lhes eram propiciadas dependiam do 
grau de simpatia. Em caso de necessidade, os escravos eram comercializados pelos patrões, enquanto que os agregados eram despedidos.

Cabral assim descreve esta realidade:

Assim constituíam eles uma população sem terra, sem gado, sem outros bens senão os recebidos na munificiência do senhores. Duas ou três vacas leiteiras que possuíssem e uma rocinha plantada nas terras do latifundiário eram tudo o que realmente possuíam. A sua pobreza era permanente, embora permanentemente fosse a necessidade de sua existência, a fim de ser mantida a conservação do latifúndio e a prosperidade do pastoreio. (CABRAL, 1979, p. 89).

Aujor Ávila da Luz (1999), analisando a organização social, destaca a existência da classe rica formada pelos fazendeiros. E classifica também a existência de uma plebe, formada por peões agregados e trabalhadores braçais. Quanto aos primeiros povoadores, Luz destaca: "interessantes estes primeiros povoadores, uns, fugidos da justiça; outros, perseguidos por dívidas insolúveis, outros dominados pela ambição ou movidos pelo salutar desejo de melhorar sua situação". (LUZ, 1999, p.104).

Dentro dessa estrutura econômica se consolidou a propriedade privada. Em períodos anteriores, a terra era de usufruto comum, de tal sorte que as relações entre proprietários e camaradas se assemelhavam às relações entre senhores e escravos. A situação de pobreza criou na população um relativo desinteresse pela acumulação, desapego, desprendimento dos bens materiais e de modo especial da terra. Com o surgimento da lei de terras, as sesmarias ou terras devolutas que ainda não haviam sido medidas ou cultivadas passaram a ser legalizadas mediante pagamento. Do ponto de vista de uma educação social, observa-se que o povo foi educado na perspectiva da subserviência, ou seja , dentro do adágio popular que se projeta através dos diferentes momentos de sua história, deixando resquícios bastante fortes após cem anos do Contestado: "manda quem pode...obedece quem precisa".

De acordo com Vinhas de Queiroz (1977, p.43), a hierarquia social encontrava-se escalonada: coronéis, fazendeiros, criadores ou meio-fazendeiros, lavradores, agregados e peões.

Nesse sistema, cada município tinha o seu chefe político, o coronel, que normalmente era um dos maiores fazendeiros da região, sendo que os interesses de vários coronéis se entrelaçavam. No rol social, havia coronéis de menor importância, muitas vezes, eventuais substitutos dos mais renomados.

Cada Município tinha o seu chefe político ou mandachuva que era o coronel por excelência, estreitamente vinculado, por laços de colaboração e de ajuda mútua, aos demais coronéis da área e ao governo do respectivo Estado, - um governo constituído de coronéis, ao qual se apoiava em troca de favores e carta branca para governar discricionariamente o município. (CABRAL, 1979, p. 89).

De acordo com Aujor Ávila da Luz, as condições sociais produzidas no planalto catarinense fizeram emergir o capanguismo, que estimulava o povo baixo e inculto a praticá-lo. O autor relata a situação da seguinte maneira:

O ambiente criminógeno, que predominava no planalto catarinense, constitui-se assim, pela ação lenta mais acentuada de diversos fatores: primeiro, as deficiências econômicas ligando pela servidão muitos homens pobres a uns poucos ricos: depois pelo analfabetismo, a ignorância e a incultura, a vida rústica não oferecendo condições de 
aperfeiçoamento : a justiça cara e ausente, fazendo com que o homem do campo achasse melhor uma má arrumação do que uma causa ganha e preferisse, nos seus litígios e contendas, desiludidos dos recursos judiciários, apelar diretamente para as armas, substituindo o Direito pelo revolver smith ou pela carabina winchester [...].(LUZ, 1999, p. 108, grifos no original).

Uma das categorias abordadas pelo autor é a dos camponeses, que ele divide em camponeses pobres, peões, agregados e empreiteiros; camponeses médios, considerados como lavradores e pequenos criadores; e camponeses ricos, que podiam ser encontrados no grupo de pequenos criadores, empreiteiros de erva-mate e produtores de fumo. Queiroz (1977), ressalta ainda que esses grupos vieram constituir a massa de participantes nos acontecimentos da Guerra do Contestado entre 1912 e 1916.

Quanto à camada dominante, Vinhas de Queiroz (1977, p.48) observa:

Por outro lado, era nítida dentro da classe dos grandes proprietários de terras a separação entre a camada superior, a dos coronéis - que em geral eram os homens mais ricos de cada município e monopolizavam o poder político -, e os demais fazendeiros, que àquele tempo e naquela área nem sempre tinham a propriedade de suas terras, mas apenas a posse. Estes últimos, quando muito eram capitães e não coronéis da Guarda Nacional, e seu comportamento foi bastante diverso durante a Guerra Sertaneja.

Torna-se importante ressaltar que, dentro dessa estrutura, é evidente a falta de instrução, de escolas, de meios de comunicação, assim como a presença de um povo revoltado por falta de justiça. Os pobres ligavam-se aos mais abastados por motivos econômicos, sentimentais e políticos. Nesse espírito de centralização do poder, gerava-se o coronelismo onipotente, consolidavam-se chefes políticos, caudilhos e mercenários, cujos nomes se tornaram célebres dentro dos sertões catarinenses. Inserido nesta estrutura criouse o sistema de compadrio em que os subjugados tinham nas pessoas influentes proteção em todos os sentidos. A respeito dos laços de compadrio, Queiroz escreve:

Laços de compadrio e afilhadagem ligavam ainda mais o fazendeiro ao pessoal que não pertencia à própria família: em certos casos, esses laços envolviam posseiros isolados, que residiam mais ou menos distantes da fazenda [...] Procurava-se manter, isto sim, o mito de que não havia antagonismo, no interior do grupo, e realmente, a crença de que o fazendeiro seria o maior e mais sincero defensor de seus parentes, compadres e afilhados se conservava até que a vida se encarregasse de demonstrar o oposto. (QUEIROZ apud VALENTINI, 1998, p.34).

Destaca-se que, na região, existiam grupos rivais e antagônicos que disputavam a chefia política. Nem sempre chegavam ao grau de inimigos mortais, porém, quando essa situação se dava, verificava-se uma separação de todos os membros da grande família. As divergências, às vezes, tornavam-se profundas, sendo incorporadas como um patrimônio geral do grupo. Cada chefe conhecia todo o seu clã e, inclusive, os resultados eleitorais eram sabidos antes do pleito. Nessa região, muito sangue foi derramado e muitas tocaias articuladas como forma de eliminar os adversários. A região do Contestado sofreu fortes consequências da lei de Terras de 1850, da presença do capitalismo internacional responsável pela construção da ferrovia e da predatória exploração da madeira. Essa lei teve seu processo de regulamentação em 1854 e, de maneira geral, voltava-se à expropriação da terra. Tinha entre seus objetivos o povoamento da região sul pelos imigrantes e atender aos interesses da burguesia agrária emergente, concedendo-lhe títulos de terra. A legislação teve um marco muito importante na compra e venda das terras, 
superando o sistema tradicional da posse e deixando sem o acesso à terra a grande massa dos marginalizados, ou seja, os índios e os caboclos.

Quanto à pequena propriedade, Andrade faz a seguinte observação:

A pequena propriedade dificilmente subsistia próxima ao latifúndio, pois os donos destes facilmente expandiam seus domínios, ora forçando a venda por parte dos pequenos proprietários, ora simplesmente expulsando-os da gleba que exploravam [...]. Quando os moradores ensaiavam alguma resistência, jagunços eram utilizados para expulsá-los ou assassiná-los Deste modo a grande propriedade se manteve e se expandiu em função do poder e da violência dos proprietários. (ANDRADE, 1987, p. 40).

O Contestado não foge à regra daquilo que se observa nos movimentos messiânicos. Queiroz (1977) salienta que, ao lado de José Maria, os camponeses lutaram movidos por uma exaltação mística e até mesmo em um verdadeiro estado de possessão, cabe ressaltar a importância dos monges como educadores sociais.

O capitalismo revoluciona o modo de viver e de trabalhar do camponês, e os relacionamentos acontecem de forma vertical. Nessa situação, os interesses do capital preponderam, sendo o camponês tratado de cima para baixo. Ianni (1995) explica que, mesmo sofrendo essa condição subalterna, o camponês reage de diferentes modalidades: resignação, fatalismo, banditismo, tocaia, revoltas, messianismo. Os grupos dominantes da América Latina são moldados com o jeito e o modo de ser dos conquistadores, estando o camponês numa situação desfavorável e sendo colocado à margem de todo o processo social, político e econômico.

Sobre essas questões, Ianni assim se expressa:

Às vezes é cidadão a meias. Outras vezes, pode contar com uma cidadania totalmente regulada, tutelada ou outorgada. Está sujeito à violência estatal, enquanto cidadão presuntivo, e sujeito à violência privada, do latifundiário ou coronel, enquanto trabalhador rural atrelado às estruturas locais, municipais ou regionais do mando e do desmando. Sob essas condições, o camponês é colocado em posição totalmente subalterna no espaço de mercado e das estruturas jurídico-políticas nacionais. (IANNI, 1995, p.33).

O que certamente irritou os camponeses do Contestado foi a facilidade de aquisição e legalização das terras com o apoio do Estado, por parte dos sindicatos estrangeiros. Essa situação gerou o descaso com relação aos camponeses que ficaram relegados sem nenhuma política social. Para garantir suas posses, os representantes utilizavam-se da violência armada. Queiroz faz a seguinte observação: "Um profundo conhecedor da área confirma que entre as razões mais fortes por que os sertanejos tomavam parte da Guerra do Contestado estava 'a explosão de um sentimento de revolta contra as grandes concessões de terra, as quais vinham escorraçá-los daquilo que entendiam ser a propriedade"”. (Queiroz, 1977, p. 1790).

Esse sentimento de ter sido ludibriado e, ao mesmo tempo, ter perdido suas posses para os estrangeiros, com a aquiescência dos órgãos governamentais, fazia parte do cotidiano dos camponeses. A questão da terra sem dúvida transformou-se numa dimensão consciente do ideal de luta dos camponeses. O elemento comunitário se fazia presente no processo revolucionário.

Sobre esta questão Marx e Engels declaram:

[...] É somente na comunidade [com os outros que cada] indivíduo possui os meios para desenvolver as suas faculdades em todos os sentidos; é 
somente na comunidade que a liberdade pessoal é possível [...] $\mathrm{Na}$ comunidade real, os indivíduos adquirem sua liberdade simultaneamente com sua associação, graças a essa associação e nela. (MARX; ENGELS, 2002, p. 92-93).

O movimento do Contestado, de acordo com Rosa (2011), reuniu homens das diversas classes sociais da região, exceto a camada dominante que era formada pelos coronéis. Ao que se sabe, nunca se tornou explícita a reivindicação de derrubada do coronelismo. Frente à complexidade de organização, diferentes concepções e grupos se associaram ao movimento. A guerra do Contestado toma um rumo de descontrole uma vez que, no seu início, principalmente em Taquaruçu, o espírito da reunião dos camponeses era de cunho altamente comunitário e religioso.

Machado assim descreve as crueldades praticadas no final da Guerra do Contestado:

Os momentos finais da irmandade cabocla foram marcados pela divergência explícita de render-se ou não às tropas do governo. Como Adeodato era partidário da continuação da guerra, ele via os capitulacionistas como traidores em potencial, uma vez que, não raro, havia vários 'ex-fanáticos' entre os vaqueanos a serviço das tropas legais. Apesar das inúmeras brutalidades praticadas por Adeodato, não há relato que indique estas mortes se teriam dado por 'vontade divina' ou para "tirar o diabo do corpo". As execuções aconteciam por problemas de disciplina interna ou por tentativa de fuga. (MACHADO, 2004, p.308).

No final da Guerra do Contestado, muitas tensões e divisões aconteceram dentro dos redutos. As tropas oficiais aproveitaram-se da situação para efetuar negociações. Ocorreu um impasse político entre as forças que estavam no Contestado. Do lado do Exército, tinha-se a posição de que a referida força deveria se retirar da região e a repressão dos remanescentes do Contestado deveria ser feita pelas forças policiais do Paraná e Santa Catarina.

Um aspecto a ser refletido a partir da visão institucional refere-se à questão do posicionamento do Estado, que mais uma vez se colocou ao lado do capital. Por outro lado, eximiu-se de qualquer responsabilidade quando classificou os vencidos como seres da pior espécie, bandidos, bandoleiros. Essa concepção esteve impregnada, através dos tempos, no imaginário de nossa população, servindo para a manutenção dos mecanismos de poder.

Uma hipótese que se levanta ao efetuarmos uma análise do movimento social do Contestado é que este episódio perpassou historicamente as gerações com a visão da historiografia oficial. Presume-se que, no final do movimento, devido ao clima de terror gerado na região, assinalado pela fome, morte, criaram-se o silêncio e o medo que se reproduziram através dos tempos. Segundo Rosa (2011), o povo da região serrana ainda trilha num deserto esperando a volta do exército encantado de São Sebastião. No Planalto Catarinense, estruturado a partir da ótica de exploração capitalista selvagem, existe um povo que caminha e que luta pela sua emancipação. Nossos camponeses morreram, foram 4, 8, 10 ou 20 mil nesse conflito rural. Não, eles não morreram. O sonho de liberdade, de emancipação permanece na memória dos vivos que hoje lutam para a construção de outra história onde haja pão, teto e letras, enfim a dignidade.

\section{Da educação instituída na região e seus desdobramentos na atualidade}

É importante analisar os impactos sofridos em todos os recantos de nosso planeta 
em consequência das transformações por que passa o mundo atual. É também importante observar, nesse contexto, o papel do Estado e da sociedade civil no processo de educação e o espaço ocupado pelo cidadão nessa sociedade. A respeito da questão Bobbio afirma:

O Estado, ou qualquer outra sociedade organizada onde existe uma esfera pública, não importa se total ou parcial, é caracterizado por relações de subordinação entre governantes e governados, ou melhor, entre detentores do poder de comando e destinatários do dever de obediência, que são relações entre desiguais; [...]. (BOBBIO, 1995, p. $15)$.

O Estado moderno assume, de certa forma, um papel de dominação quase que absoluta decorrente de sua real função na atualidade. Esse Estado por consequência de sua atuação sofre pressões advindas dos conflitos e mecanismos internos da sociedade. As pressões são decorrentes das condições impostas pela elite inserida dentro do mesmo contexto social e que domina o Estado. Nesta investigação, adota-se o conceito de sociedade civil para designar as instituições que representam a vida social, sendo uma delas o Estado. No processo, o Estado ou é representante da sociedade civil ou, caso contrário, não terá a sua legitimidade. A luta pelo poder entre o Estado e a sociedade civil é assim observada por Dallarosa (1998, p.24): “[...] constitui o fundamento do que se entende por cidadania, sendo que o cidadão é aquele que faz o Estado e não aquele que é apenas instituído pelo Estado".

Ressalta-se que o Estado instituído é sustentado pela propriedade privada, sendo representante dos grupos que mantêm o poder econômico, não correspondendo aos reais interesses da sociedade civil, ou seja, as políticas advindas desse poder representam os interesses das classes que dominam, relegando a um segundo plano os legítimos interesses da população. Marx e Engels (1986, p. 97), comentam:

\begin{abstract}
A burguesia, por ser uma classe e não mais um estamento é obrigada a organizar-se nacionalmente, e não mais localmente, e dar uma forma geral a seu interesse médio. Através da emancipação da propriedade privada em relação à comunidade, o Estado adquire uma existência particular ao lado e fora da sociedade civil; mas este Estado não é mais do que a forma de organização que os burgueses necessariamente adotam, tanto no interior como no exterior, para a garantia de sua propriedade e de seus interesses.
\end{abstract}

O processo educacional de uma sociedade acontece de maneira formal e informal. Ao longo da história, a educação é uma das formas pelas quais o homem procurou a garantia de sua vida no estabelecimento das relações com os demais, bem como consigo mesmo e com o cosmo.

Podemos afirmar que, a cada modelo de sociedade desejada corresponde pelo menos um modelo de homem e de cidadão, para cuja formação a educação contribui. Educar o indivíduo para ser um cidadão ativo, agente transformador, requer que se entenda esse ser humano como portador de direitos e deveres. A partir desses fundamentos, o indivíduo toma consciência de seu lugar dentro da sociedade, estruturada de acordo com os interesses da real maioria. Nessa perspectiva, o indivíduo torna-se a razão de ser do Estado. Porém, o que se observa é que, muitas vezes, as transformações não se consolidam não por causa da compreensão crítica por parte da população, mas como adverte Freire (1976, p. 106): "[...] por causa das condições precárias em que vivem e sobrevivem, porque vêm sendo proibidas de saber, a saída é a propaganda ideológica, a 'sloganização' política e não 
o esforço crítico $[\ldots]$..."

Nesse contexto, é de grande importância o indivíduo se questionar como se situa dentro da sociedade. Torna-se fundamental situar-se na realidade histórica vivenciada em nosso país no final do século XIX e início do século XX. Nesse período o Brasil experimentou a passagem de um período monárquico para um período republicano em que as elites se perpetuaram no poder. Dentro da conjuntura mundial, políticas neocolonialistas foram implantadas juntamente com o imperialismo das grandes potências industrializadas e a dominação dos grandes grupos econômicos. Historicamente, nas primeiras décadas de nossa República, a sociedade brasileira vivenciou um Estado Oligárquico Agrário. Nesse contexto Sader (1993, p. 20), faz a seguinte indagação: "O que é o 'Estado oligárquico'? Segundo a afirmação de Augustin Cueva é a 'expressão superestrutural do processo de implantação do capitalismo como modo de produção dominante nas entidades sociais latino-americanas"”.

A educação, nesse momento, acompanhou as mudanças da época, servindo de sustentáculo à estrutura social dominante. Dentro dessa realidade é que se estrutura o processo de educação dos camponeses do Contestado. E essa dominação tem perpassado gerações, sendo o processo educacional formal e informal voltado para a passividade, ou seja, para uma adaptação ao mundo, em vez de tornar as pessoas sujeitos históricos, arquitetos e conceptores de projetos voltados às mudanças sociais. Diante do perigo representado pelo pensamento autêntico, Freire (1987) comenta brilhantemente que esse ato, caso se concretize em toda a sua magnitude, torna-se um ato perigoso para os mecanismos de poder instalados em nossa sociedade.

O movimento social do Contestado aconteceu dentro de uma estrutura de dominação que se perpetuou através das gerações, influindo na educação do povo da região. O que se observa nessa sociedade são ações centralizadoras, marcos do processo de educação opressora que se reproduz na sociedade até os dias atuais. Nesse ambiente, as pessoas são massificadas, sendo marcadas pelo terror branco que gera a cultura do medo e do silêncio.

Os marginalizados são vítimas e consequências dessa sociedade. Para não despertá-los para a busca de seus direitos, é necessário educá-los para que se tornem passivos e domesticados. Essa lógica instituída na educação formal e informal da região faz parte do passado e da realidade presente.

Em contraposição à cultura do medo e à cultura do silêncio institucionalizadas no cotidiano dos seres humanos, perpetua-se a cultura da satisfação por parte daqueles que oprimem. A respeito dessa questão coloca-se em evidência o cenário do selvagem sistema capitalista na América Latina, onde a maioria são os perdedores e a minoria os bemsucedidos. Há que se destacar que os dominadores, para manterem sua situação de privilégios, elaboram teorias buscando legitimar e naturalizar esta realidade. Nesse sentido, Cury (1995, p. 54), salienta que a educação pode ser um referencial de legitimação ou de transformação social:

A educação, embora de gênero e função específica, é produto humano e conservará o caráter dialético dos fenômenos existentes na estrutura social. Assim, ao mesmo tempo que expressa a estrutura, pode ocultá-la. De outro lado, a estrutura social gera novas exigências para a educação, que ao captá-las antecipa um modo de ser do futuro, que determina tarefas para o presente.

A concepção de educação para a cidadania assumida nesta pesquisa refere-se à totalidade social, sendo essa advinda do mesmo processo que deu origem ao ser humano 
adaptado à natureza e a si mesmo. Dallarosa (1998, p. 121), conclui:

Deste modo, a educação para a cidadania precisa necessariamente formar um novo homem que, além dos conhecimentos técnicos, possua também consciência de sua condição social e dos determinantes desta condição para que, na prática cotidiana possa fazer frente ao sistema e às circunstâncias negadoras da cidadania.

Para que formemos um cidadão ativo, torna-se básica sua educação política, a fim de que o ser humano supere a apatia e o despreparo, garantindo a consolidação da participação, do pluralismo e da democracia, elementos fundamentais para o desenvolvimento humano. Por outro lado, quando excluímos os indivíduos do acesso à educação, estaremos excluindo-os da cidadania.

O ser humano, nos diversos momentos da história da humanidade, vivenciou no seu cotidiano o preservar de certas informações passadas, destacando as que têm importante representação no presente. Através da memória histórica ou da memória social, o ser humano intervém na ordenação dos vestígios, determinando a releitura desses vestígios a partir de referenciais atuais. Le Goff (1996, p. 426), enfatiza da seguinte maneira a importância da memória social: "O estudo da memória social é um dos meios fundamentais de abordar os problemas do tempo e da história, relativamente aos quais a memória está ora em retraimento, ora em transbordamento".

Le Goff (1996, p.450) observa ainda que, nos povos sem escrita, a memória coletiva encontra-se organizada em torno de três grandes eixos: a idade coletiva do grupo, que traz em sua essência uma fundamentação mitológica, os prestígios das famílias dominantes expressos através das genealogias e o saber técnico repassado através de práticas ligadas ao fenômeno religioso. Com o surgimento da escrita, ocorreram profundas transformações na memória coletiva. O autor faz a seguinte observação sobre esse período: "Todavia, nestes tempos, o escrito desenvolve-se a par do oral e, pelo menos no grupo dos clérigos e literatos, há um equilíbrio entre memória oral e escrita, intensificando-se o recurso ao escrito como suporte da memória".

Dentro dessa perspectiva, é importante destacar que a memória do movimento social do Contestado é fortemente marcada pela oralidade, de certa maneira influenciada por uma memória da história oficial reproduzida até o momento atual. Nesse contexto, preservam-se no coletivo abordagens míticas e o culto às famílias tradicionais.

O povo, o sertanejo, o homem sofrido do sertão não fazem parte dessa história, haja vista ter sido relegado pela história oficial. Os anos oitenta são marcados pela efervescência dos movimentos sociais, da Pedagogia Crítica e da Teologia da Libertação. A escritora $^{3}$, cuja obra torna-se o ícone da história oficial de Curitibanos, assume o seguinte posicionamento em carta escrita a D. Honorato Piazzera, bispo diocesano de Lages, mostrando de certa forma a visão hegemônica dos grupos de poder. No expediente, além de condenar as ações da Igreja a partir de Puebla com a opção pelos pobres, faz a seguinte afirmação:

Eu sei que a Igreja pôs toda a sua esperança nos pobres. Pelo menos, foi o que li no mensageiro de Santo Antônio. Essa é uma grande utopia, Sr Bispo, sendo que a classe pobre, inculta e mal estruturada está já assumindo a imoralidade geral, isso porque ela própria nunca teve formação adequada como "classe trabalhadora", limpa de malícias e mentiras. Creio que não haverá o que salvar.

Esta carta ao bispo diocesano de Lages deixa transparecer, de certa maneira, a mentalidade dominante em Curitibanos, e as observações aqui feitas não têm o caráter de 
ataque direto às ideias veiculadas nesses documentos nem ao trabalho da historiadora que devemos muitas pesquisas feitas sobre a história local. Porém, o que se questiona é a concepção de seus escritos, que trazem em sua essência o pensamento dominante, tendo influência direta na educação dos habitantes no período pós-guerra como reflexo do pensamento vigente.

Na década de 80, o Brasil vivenciou o período da abertura após longos anos da ditadura militar. Nesse ambiente marcado pela crítica, vieram à tona temas como reforma agrária e voto do analfabeto. Esse pensamento foi repudiado pelo grupo hegemônico em Curitibanos que se preocupava com a manutenção do status quo. Julgamos que o pensamento da escritora traduz os interesses dos dominantes, haja vista que a escritora, considerada a maior historiadora de Curitibanos, nunca teve trabalhos como objetos de severas críticas e repressões. Sobre os temas que na época estavam no auge das discussões a autora ${ }^{4}$ comenta:

Voto do analfabeto, errado, depõe contra o povo, desestimula o aprendizado. Servirá apenas para aumentar o número de deputados na assembléia e, com o tempo, teremos uma grande liderança inepta, atrasada.

Reforma Agrária - o brasileiro, antes de receber títulos de terras, deve ser preparado para amá-la e trabalhá-la, ao contrário, venderia a gleba por qualquer preço, como aconteceu aqui, onde um cidadão trocou um lote por uma bicicleta.

As afirmativas sobre esses assuntos cruciais deixam transparecer conservadorismo e até uma postura reacionária frente a questões tão importantes para a sociedade brasileira naquele momento. Com relação ao tema Reforma Agrária, ainda nos dias atuais tem-se uma concepção conservadora quando comentada ou trazida para ser discutido na academia. No cotidiano das aulas na Universidade, onde se tenta fundamentar conteúdos ligados à História Regional com referenciais teóricos críticos, predominam a visão oficial e atitudes conservadoras. Torna-se difícil extrapolar o senso comum. Em outro expediente, a escritora $^{5}$ tece o seguinte comentário ao remeter uma carta a uma autoridade em destaque no Estado de Santa Catarina:

O Sr. já deve estar sabendo, surgiu uma nova versão sobre a origem do movimento - luta pela posse da terra - contra o qual estou me insurgindo. Por sinal, o senhor me advertiu, há anos, de que o sociólogo Maurício V. de Queiroz aproveitara-se dos fatos para impor sua doutrina comunista.

Este artigo tem por objeto uma análise do movimento social do Contestado e seu desdobramento na atualidade no setor educacional. Portanto, há que se esclarecer que o objeto desta pesquisa focaliza o processo educacional da região, principalmente no período pós-massacre. Não se tem por escopo avaliar a autora que tem vários escritos sobre o Contestado e história da região, mas certamente discutir concepções de história que exerceram grande influência no processo de educação do povo dessa região. A história aqui transmitida através dos tempos foi a história oficial, ou seja, a história do Estado trabalhada numa perspectiva positivista, enaltecendo heróis, fatos, famílias tradicionais, coronéis e, relegando a maioria da população a meros coadjuvantes da "verdadeira história". Essa concepção fica bem clara, na seguinte afirmação da escritora ${ }^{6}$ em uma carta ao Dr. David Carneiro: "Os autores de hoje, fundamentando-se na teoria marxista, eliminando o fanatismo, criaram o mito do caboclo-jagunço-herói”. 


\section{Considerações finais}

Para a compreensão do Contestado como movimento social e seu desdobramento na atual situação educacional da região, fez-se necessária análise de vários aspectos, haja vista que o processo educacional da região sofreu e sofre inúmeras influências desde a guerra do Contestado até os dias atuais.

Do ponto de vista local, tem-se que o Contestado é uma região privilegiadíssima, eis que se encontra localizada no centro de Santa Catarina e posicionada estrategicamente em relação às grandes capitais e cidades da Região Sul. A natureza lhe é pródiga em climatologia e recursos naturais, como a fauna, a flora e hidrográficos.

Do ponto de vista geopolítico, a região - no decorrer de sua história - sofreu profundas influências advindas da formação do Estado de Santa Catarina, tendo como questão inicial o povoamento do Estado, que seguiu a mesma lógica do povoamento brasileiro, privilegiando o litoral e isolando o interior; além das influências da questão de Palmas e da Questão do Contestado, resolvidas de forma pacífica. Ressalte-se que a Guerra do Contestado foi marcada pela morte de inúmeras pessoas na região. Nessas questões, há que se realçar a inexistência de preocupação por parte dos poderes públicos com as classes excluídas do planalto.

Nesse cenário, após a dizimação do elemento indígena pelos sertanistas, chamados bugreiros, que agiam de acordo com os interesses do capital, a região foi ocupada pelos tropeiros e pelos imigrantes, de cuja miscigenação surgiu a figura do caboclo, o homem do Contestado.

Esse caboclo que tinha a posse da terra, além de excluído por parte do Estado de todas as políticas sociais, foi mais uma vez alijado de todo o acesso às terras no processo de legalização da estrutura fundiária com base na lei das Terras aprovada em 1850. O caboclo - que havia vivenciado na região a batalha da Revolução Farroupilha - não consegue avaliar as profundas consequências políticas, sociais e econômicas decorrentes dessa lei. O homem do Contestado, que era o proprietário da terra de fato, mas não de direito, perdeu a posse da terra. A terra, de espaço de sobrevivência, seguindo a concepção do sistema capitalista, tornar-se instrumento de poder e de riqueza de uma minoria privilegiada, ampliando o fosso que separa a região da riqueza e a da pobreza.

Nesse palco, a pecuária veio a assumir o papel de atividade econômica principal através da formação da sociedade pastoril. Essa sociedade caracterizou-se por ser eminentemente centralizadora, cujo poder se concentrava nas mãos do fazendeiro e de sua família, sendo que os serviços da atividade pastoril eram executados pelos agregados, peões e escravos.

Desse modo, essa estruturação deixou profundas marcas nos mecanismos de poder que se consolidou com a figura do coronel que assume o comando da região, com posturas escamoteadas ao longo da história até os dias de hoje.

A chegada do capitalismo internacional marcou, na região, a destruição da ordem anterior, ou seja, para o capitalismo se estruturar teria que se excluir a lógica vigente até então. O sertanejo foi excluído de todo o processo de desenvolvimento, não tendo acesso aos benefícios proporcionados pelo desenvolvimento da região.

Rosa (2011), concorda com diversos autores, dentre eles Vinhas de Queiroz, Paulo Pinheiro Machado, Euclides Felippe, Marli Auras, que apontam como as principais causas da Guerra do Contestado: o analfabetismo, a miséria da população do interior e o isolamento em relação litoral de Santa Catarina, a espoliação das terras dos sertanejos, as forças do capitalismo internacional, a política regional e as políticas governamentais que privilegiavam as classes abastadas dos fazendeiros. 
O messianismo na região do Contestado caracterizou-se pela liderança carismática de José Maria. Essa autoridade está ligada aos poderes extracotidianos, ou qualidades, que surgiriam de um carisma, o que lhes conferiu autoridade diante da comunidade dos sertanejos no movimento social do Contestado. A política local encontrava-se nas mãos dos coronéis que eram os representantes do poder econômico. Esses eram subservientes e articulavam-se com as outras esferas de poder. Essa lógica de poder político se prolonga até os dias atuais, sendo necessário a busca de alternativas que tragam projetos com outras perspectivas para a região.

O camponês do Contestado sofreu profundos impactos decorrentes da lei das Terras, uma vez que esta beneficiava o grande produtor. Portanto, as melhores terras pertenciam ao fazendeiro, cabendo aos colonos os lugares distantes e de pouca produtividade. Diante das dificuldades enfrentadas pelos camponeses, foi criada uma conjuntura onde os grupos dominantes, além de explorarem a mão-de-obra economicamente, dominavam o sertanejo politicamente. A mão-de-obra nacional foi classificada como preguiçosa, vadia, ociosa e indisciplinada para o trabalho sistemático.

Levando-se em conta, pois, esse processo opressivo, uma das alternativas dos camponeses foi a revolução. Na essência dos movimentos sociais encontra-se o retorno à simplicidade.

A educação libertadora, no Brasil, é colocada por alguns segmentos como algo do passado, ultrapassado. Em contraposição a isto, afirma-se que, diante do processo econômico excludente, somente quando houver superação dos vários tipos de miséria é que a educação libertadora estará ultrapassada. Portanto, mesmo enfrentando a correnteza das políticas educacionais traçadas de cima para baixo, das ingerências políticas e das influências dos organismos internacionais, os pressupostos de uma educação libertadora se fazem necessários no sentido de resgatar a identidade do homem catarinense e, de modo especial, do homem do Contestado. Torna-se importante que a tônica epistemológica de uma educação libertadora assentada no ser mais possibilite aos excluídos da região do Contestado descobrirem-se como sujeitos da história.

É necessário que os que trabalham no setor educacional repensem o currículo escolar da educação Infantil à Universidade e trabalhem por uma educação que traga, na sua essência, elementos da crítica, da problematização e da humanização, esclarecido que não se está propondo o uso da força como saída para libertação, mas sim uma perspectiva freiriana, a libertação do oprimido e do opressor e a transformação real das estruturas que oprimem.

O movimento social do Contestado aconteceu dentro de um contexto marcado pela dominação. A educação instituída pelos dominantes se perpetuou através de gerações, influindo decisivamente na educação do povo dessa região. O que se observa nesse projeto são ações centralizadoras, marco de uma educação repressora que se reproduz até os nossos dias. Nesse ambiente os dominados são massificados, o terror branco é utilizado como arma geradora da cultura do medo e do silêncio. Essa prática anula o poder de criação do homem do Contestado, estimulando a apatia e a submissão, satisfazendo os interesses dos dominantes. Os excluídos são vítimas desse projeto. Para não despertá-los a buscar seus direitos, impõe-se aos que educam torná-los passivos e domesticados. Por outro lado, perpetua-se a cultura da satisfação entre os bem sucedidos, os vencedores.

Acredita-se que, para sair dessa situação, para a formação de cidadãos ativos, é imprescindível uma educação sociopolítica, capaz de fazer com que o ser humano supere a apatia e o despreparo e se volte para participação, o pluralismo e a democracia, fundamentais para o desenvolvimento humano. 


\section{Referências}

ANDRADE, Manuel Correia de. Abolição e reforma agrária. São Paulo: Ática, 1987.

BOBBIO, Norberto. Estado, governo e sociedade: para uma teoria geral da política. Tradução de Marco Aurélio Nogueira. Rio de Janeiro: 1995.

CABRAL, Oswaldo Rodrigues. A campanha do Contestado. Florianópolis: Editora Lunardelli, 1979.

CURY, Carlos R. Jamil. Educação e contradição. São Paulo: Cortez, 1995.

DALLAROSA, Adair Angelo. Estado, educação e cidadania. Caçador: Editora Universidade do Contestado, 1998.

FREIRE, Paulo. Ação cultural para a liberdade. Rio de Janeiro: Paz e Terra, 1976.

IANNI, Octávio. Os movimentos camponeses. IN: Santos, José Vicente dos. Revoluções camponesas na América Latina. Campinas: Editora Unicamp, 1985.

LE GOFF, Jacques. História e memória. Tradução de Bernardo Leitão. Campinas: Unicamp, 1996.

LEMOS, Zélia de Andrade .[Carta ao Bispo da Diocese de Lages.] 2 f. 09/12/1985.

Museu Antônio Granemann -Curitibanos-SC.

[Carta a Fr. Félix Fegger.] 24/07/1985. 1. f. Arquivo do Museu Histórico Antônio Granemann de Curitibanos. Pastas de 1973 a 1990.

[Carta a Fr. Félix Fegger.] 24/07/1985. 1. f. Arquivo do Museu Histórico Antônio

Granemann de Curitibanos. Pastas de 1973 a 1990.

.[Carta ao Dr. David. Carneiro.] 13/12/1994.. f. Arquivo do Museu Histórico

Antônio Granemann de Curitibanos. Pastas de 1973 a 1990

LUZ, Aujor Ávila da. Os fanáticos: crimes e aberrações da religiosidade de nossos caboclos contribuição para o estudo da antropossociologia criminal do movimento dos fanáticos em SC. Florianópolis: Editora da UFSC, 1999.

KARL, Marx; ENGELS Friederich . A ideologia Alemã. Tradução de José Carlos Bruni e Marcos Aurélio Nogueira. São Paulo Hucitec, 1986.

. A ideologia Alemã. Tradução de Luís Cláudio de Castro e Costa. São Paulo:

Martins Fontes, 2002.

MACHADO, Paulo Pinheiro. Um estudo sobre as origens e a formação política das lideranças sertanejas do Contestado. Tese de Doutorado em História. Campinas: UNICAMP, 2001.

ROSA, Geraldo Antônio da . O Contestado: a práxis educativa de um movimento social. Campinas: Mercado de Letras, 2011.

QUEIROZ, Maurício Vinhas de. Messianismo e conflito social. São Paulo: Ática, 1977.

SADER, Emir. Estado e política em Marx. São Paulo: Cortez, 1993.

VALENTINI, Delmir José. Da cidade santa à corte celeste: Memórias de sertanejos e a Guerra do Contestado. Caçador: Universidade do Contestado, 1988. 


\section{Notas}

${ }^{1}$ Doutor em Teologia: Religião e Educação, docente do Programa de Mestrado em Educação da Universidade do Planalto Catarinense-UNIPLAC, Lages-SC, e-mail: geraldorosa06@gmail.com

${ }^{2}$ Doutor em Educação, docente do Programa de Mestrado em Educação da Universidade do Planalto Catarinense-UNIPLAC, Lages-SC. (In memoriam).

${ }^{3}$ LEMOS, Zélia de Andrade .[Carta ao Bispo da Diocese de Lages.] 2 f. 09/12/1985. Museu Antônio Granemann de Curitibanos. Pastas de 1973 a 1990.

${ }^{4}$ LEMOS, Zélia de Andrade. [Carta a Fr. Félix Fegger.] 24/07/1985. 1. f. Arquivo do Museu Histórico Antônio Granemann de Curitibanos. Pastas de 1973 a 1990.

${ }^{5}$ LEMOS, Zélia de Andrade. [Carta a Fr. Félix Fegger.] 24/07/1985. 1. f. Arquivo do Museu Histórico Antônio Granemann de Curitibanos. Pastas de 1973 a 1990.

${ }^{6}$ Lemos, [Carta ao Dr. David. Carneiro.] 13/12/1994.

Recebido em março-13

Aprovado em outubro-13 